\title{
Analysis of pediatric head injury from falls
}

\author{
K. Anthony Kim, Michael Y. Wang, M.D., Pamela M. Griffith, R.N.C., \\ Susan Summers, R.N., AND Michael L. LeVy, M.D. \\ Division of Neurosurgery and Trauma Program, Children's Hospital of Los Angeles, \\ Los Angeles, California
}

The authors conducted a study to describe the incidence and types of fall-related head injury observed at a pediatric trauma center.

We performed a retrospective analysis of all patients under 15 years of age treated for fall-related trauma between 1992 and 1998. Falls were classified as low ( $<15$ feet) and high level ( $\geq 15$ feet).

Seven hundred twenty-nine cases were identified with a mortality rate of $1.7 \%$. A fall of greater than 15 feet (high-level fall) was associated with a higher mortality rate than low-level falls $(2.4 \%$ compared with $1.0 \%$, respectively). Ninety-eight patients had sustained a calvarial fracture and 93 experienced a basal skull fracture. Twenty-six patients had suffered a cerebral contusion, 25 a subarachnoid hemorrhage, 22 a subdural hematoma, and 12 had an epidural hematoma. Forty-nine patients required surgery for traumatic injuries; of these, 10 underwent craniotomy for evacuation of a blood clot. Height was not predictive of the Glasgow Coma Scale (GCS) score. In all four deaths resulting from a low-level fall there was an admission GCS score of 3, and abnormal findings were demonstrated on computerized tomography scanning. Death from high-level falls was attributable to either intracranial injuries $(50 \%)$ or severe extracranial injuries $(50 \%)$.

Intracranial injury is the major source of fall-related death in children and, unlike extracranial insults, brain injuries are sustained with equal frequency from low- and high-level falls in this population. The only cause of mortality from low-level falls was intracranial injury. Trauma triage criteria must account for these differences in the pediatric population.

KeY WordS • Glasgow Coma Scale • head injury • pediatric • trauma • fall

Unintentional falls are a leading cause of morbidity and mortality in children and adolescents. Considering all pediatric trauma, falls account for the most common reason for an emergency department visit and are the fourth leading cause of trauma-related death, ranking behind motor vehicle accidents, fires, and drowning. ${ }^{3,6,7,10}$ Overall, falls accounted for $5.9 \%$ of childhood deaths. ${ }^{4}$

The injury patterns following a fall differ between children and adults. The proportionally greater cephalic mass in children increases the likelihood of a fall-related head injury. ${ }^{4}$ However, young children appear to suffer fewer extracranial injuries than adults when the fall occurs from the same height. ${ }^{8,11}$

To elucidate factors associated with head injury in pediatric fall victims, we undertook an analysis of pediatric falls at an institution in which these injuries are particularly common.

Abbreviations used in this paper: $\mathrm{CT}=$ computerized tomography; GCS = Galsgow Coma Scale.

\section{CLINICAL MATERIAL AND METHODS}

The records of all fall victims treated at the Children's Hospital of Los Angeles over a seven-year period (19921998) were retrospectively reviewed. This hospital serves as the only American College of Surgeons--verified Pediatric Level I Trauma Center in Los Angeles County, serving 2.4 million children under 15 years of age and receiving approximately $25 \%$ of all pediatric trauma patients in the region.

Cases were identified through the hospital's regional trauma database, and all cases satisfied either trauma activation criteria or were specifically triaged for trauma center evaluation. All patients were under 15 years of age and suffered a fall as the primary mechanism of blunt injury (however, patients who suffered a fall, for example, after being ejected as a result of a motor vehicle accident were excluded).

Seven hundred eighty-four cases were identified, and complete records were available for 729 patients. International Classification of Diseases-9 codes, Injury Severity Score, GCS score, neuroimaging results, disposition, hospital length of stay, medical costs, and outcome were all 
reviewed. The height of the fall was determined from witness and paramedic accounts.

\section{RESULTS}

\section{Mechanisms of Injury and Fall Characteristics}

Of the 729 patients, 424 were boys (male/female ratio 1.4:1). The age-specific incidence rose at age 2 years when mobility increases, and a second rise was demonstrated in adolescence as risk-taking and suicidal behaviors increase (Fig. 1).

Falls were classified as high level ( $\geq 15$ feet) in $46.1 \%$ or low level $(<15$ feet) in $52.9 \%$ of our patients. This height dichotomy reflects current trauma triage criteria as predictors of the severity of injury. There was no correlation between the height of fall and admission GCS score, and the distribution of GCS scores was similar between patients who sustained low- and high-level falls (Fig. 2).

The most common site of an accident was a fall from a window (19.9\%), balcony (13.9\%), stairs (11\%), furniture $(7.6 \%)$, tripping $(6.5 \%)$, walkers $(5.2 \%)$, and play equipment $(3.1 \%)$. Fifty-two falls were at ground level after tripping. Fifty-seven percent of patients suffered injuries at home. At least $5.9 \%$ of patients sustained a fall while at school (Table 1).

\section{Head Injuries}

Forty-four percent of all patients underwent head CT scanning. Abnormal findings were demonstrated in all patients who underwent head CT scanning and later died. Abnormal findings were identified on 175 of 322 CT scans. Ninety-eight patients sustained a calvarial fracture and 93 a basal skull fracture. There were 26 patients with cerebral contusions, 25 with subarachnoid hemorrhage, 22 with a subdural hematoma, and 12 with an epidural hema- toma. Ten patients required a craniotomy for evacuation of a blood clot. Eight percent of patients died after undergoing a neurosurgical operation.

Falls from a height of greater than 15 feet were not associated with a higher incidence of intracranial bleeding (subdural, epidural, subarachnoid, or intracerebral hemorrhage) (Table 2), and most hemorrhages related to lowlevel falls occurred at 6 feet or less (Table 3). In $96 \%$ of these cases there was no clinical evidence of child abuse, despite investigation and workup by the Suspected Child Abuse and Neglect team.

The GCS scores obtained in patients who sustained a low-level fall were a poor predictor of intracranial bleeding. In $47 \%$ of these patients with intracranial bleeding an emergency room GCS score of 13 to 15 was determined (Fig. 3). A high GCS score does not, therefore, eliminate the need for performing head CT scanning, even after the patient suffers a low level fall.

\section{Extracranial Injuries}

Extracranial injuries were common in this study population (Table 4). Facial (33 cases), upper-extremity (56 cases), and lower-extremity fractures (48 cases) were the most common orthopedic injuries. Cardiac (18 cases), splenic (17 cases), and hepatic injuries (10 cases) were the most common visceral injuries. Thirty-nine patients required extracranial surgery. Twenty-four operations were performed to treat orthopedic injuries, and 11 operations were performed to treat thoracoabdominal injures.

\section{Fatal Injuries}

Twelve children died (overall mortality rate 1.7\%). Eight children fell from heights of greater than 15 feet $(2.4 \%)$, and four patients fell less than 15 feet $(1.0 \%)$. Death occurred due to falls from heights ranging from 3 to 75 feet. In these 12 children falls from windows (33\%) and bal-

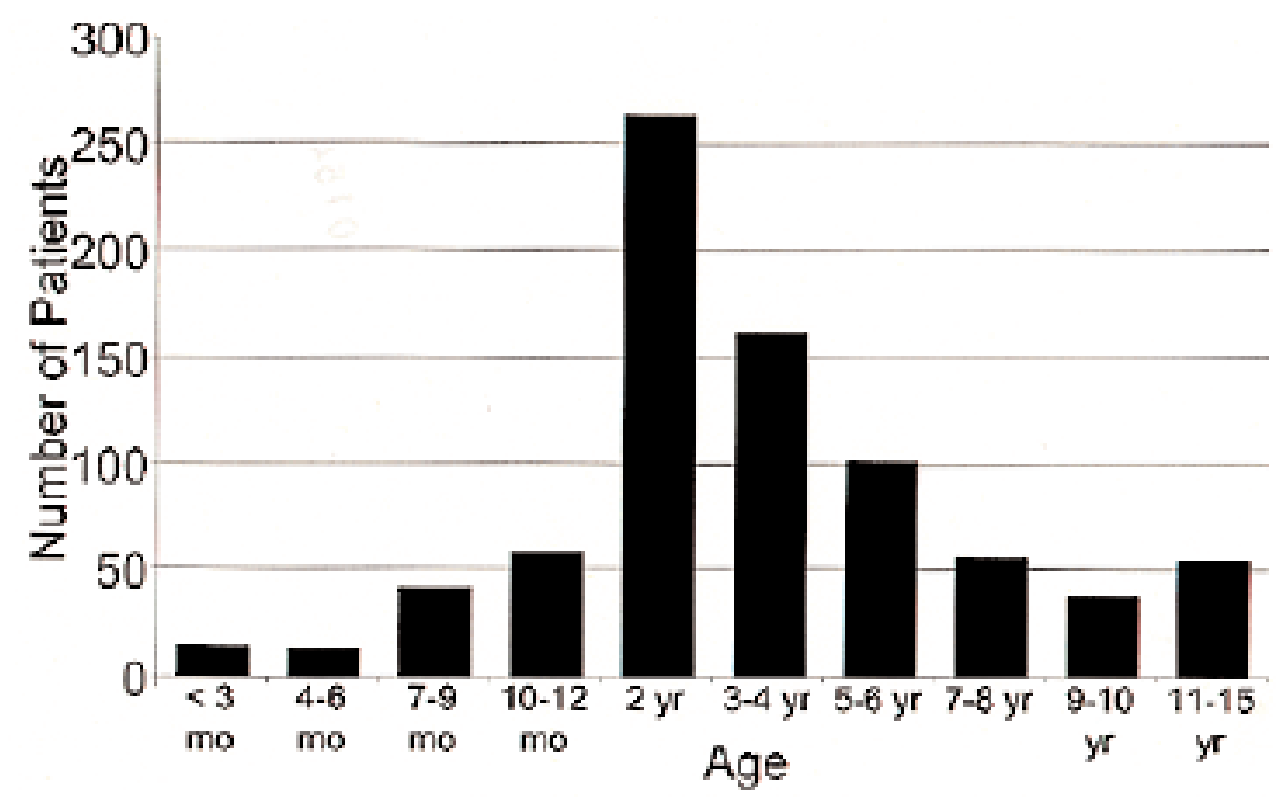

Fig. 1. Bargraph depicting the age distribution of all patients treated for fall-related trauma. 




Fig. 2. Bargraph showing comparison of GCS scores and height of fall. The number of patients who fell fewer than 15 feet, greater than or equal to 15 feet, and from an unknown height are compared for each GCS score of 3 to 15 .

conies (33\%) were the most frequent mechanisms of lethal injury (Table 5). Of the children who died, four had undergone surgery. Death from high-level falls was attributable to either intracranial injury $(50 \%)$ or multiple severe extracranial injury (50\%).

In all four fall-related deaths occurring from a height of less than 15 feet, there were emergency room GCS scores of 3 and abnormal findings on head CT scanning. There were no severe extracranial injuries, and the only source of mortality from low-level falls was cranial injury. There were no signs of child abuse in any of these four cases. Brain injuries included intracranial hemorrhage in three cases and subdural hematoma in two.

\section{DISCUSSION}

Falls are a common source of traumatic injuries in children, and the authors of several studies have shown that fall injury patterns differ between adults and children. Our experience with pediatric falls at the Children's Hospital of Los Angeles supports this contention and sheds particular light on head injuries resulting from falls.

In our study we found a $1.7 \%$ mortality rate for children who fell from any height. This is similar to a previous review of falls at our institution (1986-1990) in which a $1.2 \%$ mortality rate was demonstrated. As expected, we found a higher mortality rate when comparing high- with low-level falls (2.4\% and $1.0 \%$, respectively) with severe extracranial injuries more common in those falling greater than 15 feet. The majority of fatalities in our study (66\%) were attributable to a head injury. In a Cook County study of pediatric fall-related deaths, $86 \%$ of cases were attributable to head injury. ${ }^{4}$ Of note, the percentage of patients who fell from windows decreased from 62 to 20\%, compared with a study at our hospital from 1986 to 1990, perhaps reflecting the efforts of a fall prevention campaign. ${ }^{1,8}$
The increasing reliance on trauma triage protocols to manage fall victims has resulted in specific height-related criteria intended to predict injuries. ${ }^{9}$ Therefore, most trauma centers activate trauma response systems based on height-related criteria only when victims have fallen 15 to 20 feet or more. ${ }^{1,11}$ In our study we found a high incidence (13.7\%) of intracranial hemorrhages in patients who fell fewer than 15 feet. Although there is a selection bias for low-level falls, our sampling represents the patient population that trauma surgeons see. This corroborates the results obtained in a study of adults and children in which the

TABLE 1

FALL-RELATED CHARACTERISTICS OBTAINED IN 729 PATIENTS WITH HEAD INJURY

\begin{tabular}{lr}
\hline \hline \multicolumn{1}{c}{ Type of Fall } & No. (\%) \\
\hline from windows & $159(19.9)$ \\
from nonwindow sites & $111(13.9)$ \\
balcony & $88(11.0)$ \\
stairs & $61(7.6)$ \\
furniture & $42(5.2)$ \\
walker & $25(3.1)$ \\
play equipment & $17(2.1)$ \\
dropped & $15(1.9)$ \\
shopping cart & $11(1.4)$ \\
from vehicle & $11(1.4)$ \\
from tree & $2(0.3)$ \\
from wall & $1(0.2)$ \\
from fence & $51(6.4)$ \\
from miscellaneous "structures" & \\
ground level & $52(6.5)$ \\
"tripped" & $4(0.5)$ \\
seizure & $729(100)$ \\
total &
\end{tabular}


K. A. Kim, et al.

TABLE 2

COMPARISON OF VALUES OBTAINED IN PATIENTS WHO FELL FROM LESS THAN 15 FEET AND EQUAL TO OR GREATER THAN 15 FEET

\begin{tabular}{lrrr}
\hline \hline $\begin{array}{c}\text { Type of } \\
\text { Intracranial Bleeding }\end{array}$ & $<15$ feet & $\geq 15$ feet & Total \\
\hline subarachnoid hemorrhage & $3.4 \%$ & $3.5 \%$ & $3.4 \%$ \\
subdural hemorrhage & $4.1 \%$ & $1.5 \%$ & $2.9 \%$ \\
epidural hemorrhage & $2.6 \%$ & $0.6 \%$ & $1.6 \%$ \\
closed cerebral contusion & $2.6 \%$ & $0.9 \%$ & $1.8 \%$ \\
open cerebral contusion & $1.0 \%$ & $2.1 \%$ & $1.5 \%$ \\
total & $13.7 \%$ & $8.6 \%$ & $11.2 \%$ \\
\hline
\end{tabular}

authors found a $35 \%$ incidence of head injury in patients who fell fewer than 20 feet, suggesting a need to modify height-related criteria to account for head injuries. ${ }^{5}$ Five of our patients who fell from low-level heights required a craniotomy for evacuation of a blood clot, and the majority of hemorrhages sustained in these low-level falls resulted from a drop of six feet or less. Furthermore, $47 \%$ of these patients received an emergency room GCS score of 13 to 15 , thus limiting the utility of clinical criteria to predict the need for a head CT scan.

The outcome of pediatric falls from low heights has been somewhat controversial. In a study by Chadwick, et. al., ${ }^{2}$ a $7 \%$ mortality rate was found in children who fell 4 feet or fewer. In five of these cases there were associated injuries implicating child abuse, and in the children who fell 5 to 9 feet there was no incidence of death. This led the authors to conclude that fatal injuries caused by lowlevel falls indicate an incorrect history until proven otherwise. ${ }^{2}$ In another study the authors found no incidence of death in children who fell from heights of three stories or fewer. ${ }^{1}$ Child abuse must clearly be excluded in pediatric deaths that occur after low-level falls; however, in our study none of the four deaths from a height of fewer than 15 feet had stigmata of abuse. In all of these cases isolated head injury was the cause of death. The findings of our study corroborate those found in a study on adult falls,

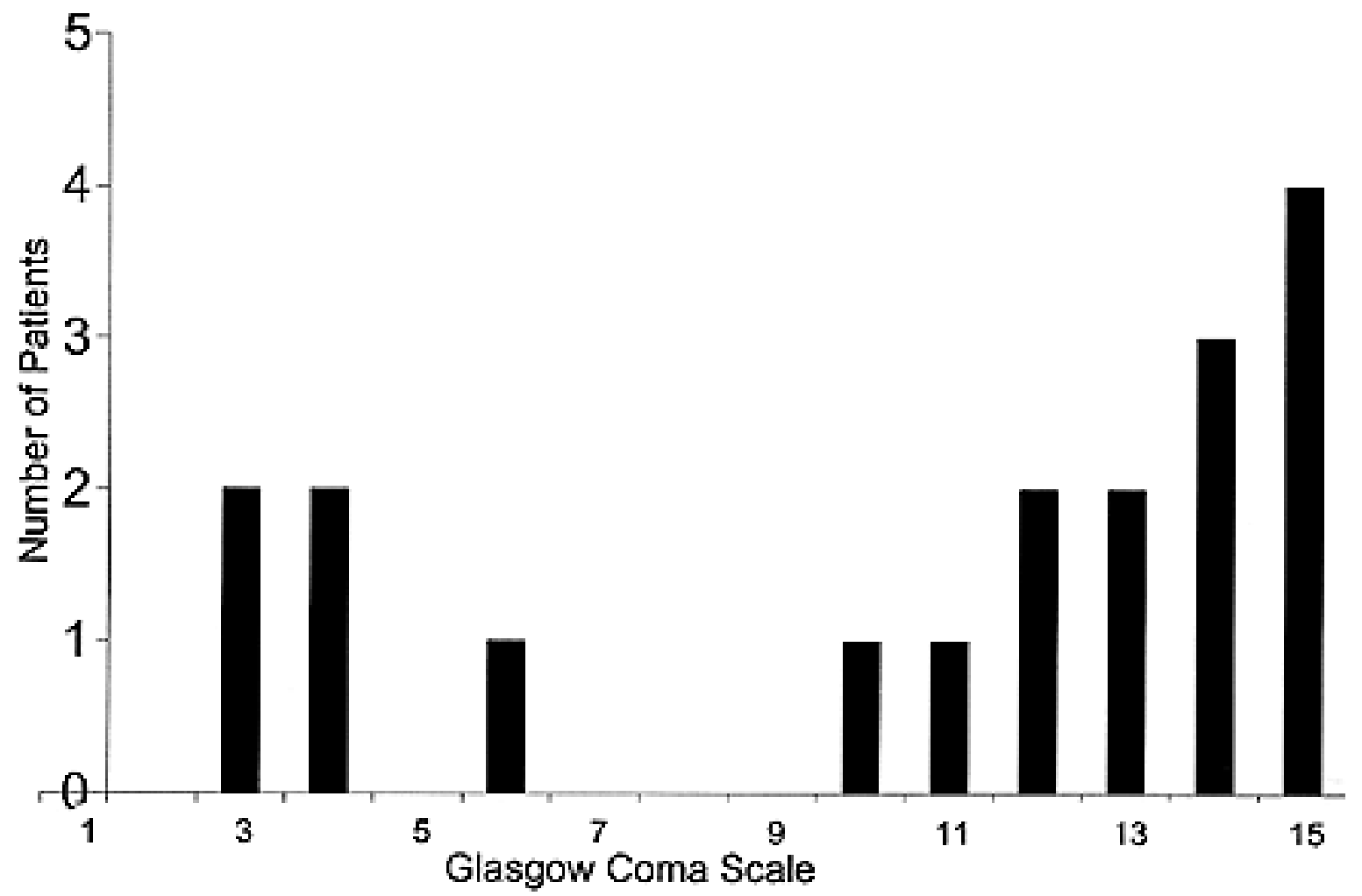

Fig. 3. Bargraph showing the GCS scores obtained in patients falling fewer than 15 feet and suffering an intracranial hemorrhage (subdural, epidural, intracerebral, or subarachnoid) who survived. 
TABLE 3

INCIDENCE OF INTRACRANIAL HEMORRHAGE IN PATIENTS WHO SUFFERED LOW-LEVEL FALLS

\begin{tabular}{rcc}
\hline \hline Height of & $\begin{array}{c}\text { No. of Patients } \\
\text { W/ Intracranial } \\
\text { Fall (feet) }\end{array}$ & $\begin{array}{c}\text { Total No. } \\
\text { of Patients } \\
\text { Who Fell }\end{array}$ \\
\hline $1-3$ feet & 22 & 134 \\
$4-6$ feet & 21 & 89 \\
$7-9$ feet & 4 & 65 \\
$10-15$ feet & 6 & 98 \\
\hline
\end{tabular}

TABLE 4

OTHER FALL-RELATED INJURIES IN THE PATIENT POPULATION*

\begin{tabular}{lrc}
\hline \hline Site of Injury & $\begin{array}{c}\text { No. of } \\
\text { Patients (\%) }\end{array}$ & $\begin{array}{c}\text { No. Who } \\
\text { Died }\end{array}$ \\
\hline fractures & & \\
facial & $33(4.51)$ & 1 \\
rib & $10(1.44)$ & 2 \\
pelvic & $8(1.14)$ & 0 \\
upper extremity & $56(7.77)$ & 1 \\
lower extremity & $48(6.61)$ & 1 \\
visceral & $7(1.04)$ & 0 \\
pneumothorax & $18(2.54)$ & 3 \\
cardiac & $1(0.14)$ & 0 \\
thoracic & $7(1.04)$ & 1 \\
abdominal & $10(1.44)$ & 2 \\
hepatic & $17(2.34)$ & 2 \\
splenic & $8(1.14)$ & 1 \\
nephric & $1(0.14)$ & 0 \\
urogenital & $2(0.34)$ & 0 \\
vascular & $2(0.34)$ & 0 \\
peripheral nerve &
\end{tabular}

* Values are based on the overall number of patients (784) who presented with fall-related injuries.

TABLE 5

ChARACTERISTICS IN 12 CASES OF DEATH AFTER FALLING

\begin{tabular}{|c|c|}
\hline Characteristic & Number \\
\hline \multicolumn{2}{|l|}{ falls from $\geq 15 \mathrm{ft}$} \\
\hline head CT scan & 3 \\
\hline abnormal CT findings & $100 \%$ \\
\hline \multicolumn{2}{|l|}{ GCS score } \\
\hline 3 & 3 \\
\hline 4 & 1 \\
\hline 5 & 1 \\
\hline 7 & 1 \\
\hline 15 & 1 \\
\hline range & $3-15$ \\
\hline fall height range (ft) & $24-75$ \\
\hline \multicolumn{2}{|l|}{ site of injury } \\
\hline window & 4 \\
\hline balcony & 3 \\
\hline other & 1 \\
\hline mortality rate & $2.4 \%$ \\
\hline \multicolumn{2}{|l|}{ falls from $<15 \mathrm{ft}$} \\
\hline head CT scan & 4 \\
\hline abnormal CT findings & $100 \%$ \\
\hline \multicolumn{2}{|l|}{ GCS score } \\
\hline 3 & 4 \\
\hline fall height range (ft) & $3-15$ \\
\hline \multicolumn{2}{|l|}{ site of injury } \\
\hline play equipment & 1 \\
\hline tripped & 1 \\
\hline balcony & 1 \\
\hline furniture & 1 \\
\hline mortality rate & $1 \%$ \\
\hline
\end{tabular}

which demonstrate an $8 \%$ mortality rate in patients who fell fewer than 20 feet. $^{5}$

One of the weaknesses of this study is that the height of the fall was obtained from recorded observation, and erroneous observations cannot be ruled out. A direct on-site measurement of the height of fall with confirmation by a second observer would be ideal to ensure accuracy and to rule out child abuse definitively.

\section{CONCLUSIONS}

In this study we found a high incidence of intracranial bleeding in patients falling from low heights. It is recommended that pediatric trauma triage criteria account for the likelihood of occult head injuries. Physicians should obtain a head CT scan in pediatric fall victims.

\section{References}

1. Barlow B, Niemirska M, Gandhi RP, et al: Ten years of experience with falls from a height in children. J Pediatri Surg 18:509-511, 1983

2. Chadwick DL, Chin S, Salerno C, et al: Deaths from falls in children: how far is fatal? J Trauma 31:1353-1355, 1991

3. Garretson LK, Galleger SS: Falls in children and youth. Pediatr Clin North Am 32:153-161, 1985

4. Hall JR, Reyes HM, Horvat M, et al: The mortality of childhood falls. J Trauma 29:1273-1275, 1989

5. Helling TS, Watkins M, Evans LL, et al: Low falls: an underappreciated mechanism of injury. J Trauma 46:453-456, 1999

6. Kraus JF, Fife D, Cox P, et al: Incidence, severity, and external causes of pediatric brain injury. Am J Dis Child 140:687-693, 1986

7. Mathers LJ, Weiss HB: Incidence and characteristics of fall-related emergency department visits. Acad Emerg Med 5: 1064-1070, 1998

8. Mosenthal AC, Livingston DH, Elcavage J, et al: Falls: epidemiology and strategies for prevention. J Trauma 38: 753-756, 1995

9. Ochsner MG, Schmidt JA, Rozycki GS, et al: The evaluation of a two-tiered trauma response system at a major trauma center: is it cost effective and safe? J Trauma 39:971-977, 1995

10. Shafi S, Gilbert JC: Minor pediatric injuries. Pediatr Clin North Am 45:831-851, 1998

11. Williams RA: Injuries in infants and small children resulting from witnessed and corroborated free falls. J Trauma 31: 1350-1352, 1991

Manuscript received December 1, 1999.

Accepted in final form December 8, 1999.

Address reprint requests to: Michael Y. Wang, M.D., Department of Neurosurgery, Room \#5000, 1200 North State Street, Los Angeles, California 90033. email: Taurusaries@ hotmail.com. 